\title{
A Study on the Oral Health Literacy and Related Factors of Mother's in Some Areas
}

\author{
Mi-Jeong Kim ${ }^{1, \dagger}$, Cha-Young $\mathrm{Lim}^{1}$, and Ju-Lee Son ${ }^{2}$ \\ ${ }^{1}$ Department of Dental Hygiene, Vision College of Jeonju, Jeonju 55069, ${ }^{2}$ Bright Dental Clinic, Jeonju 54829, \\ Korea
}

\begin{abstract}
Background: This study aims to provide basic data for development of the level-based oral health care program depending on the mother's oral health literacy by finding out how mother's oral health literacy can effect on the preschool children's oral health and behavior.

Methods: The survey was conducted on 192 mothers who have preschool children and the data were analyzed by t-test, ANOVA, multiple regression analysis to identify differences in verbal and functional oral health literacy.

Results: The study showed statistical significance $(p<0.05)$ in educational level depending on differences in verbal and functional oral health literacy by sociodemographic factor. In differences in verbal and functional literacy depending on experience of education for oral health behavior and oral health, statistical significance $(p<0.05)$ was showed highly on verbal and functional literacy in the case that subjects have an experience of education for oral health and their children have not been experienced of oral illness. And when it comes to the case that subjects have experience of education for oral health within one to two years, statistical significance was showed highly on verbal literacy. It showed that verbal and functional oral health literacy effects to oral health care behavior of children judging from results that the higher level of mother's verbal oral health literacy, the higher score of children's oral health knowledge, attitude and behavior.

Conclusion: It is necessary to develop the systematic program which is appropriate for characteristics of each oral period in childhood depending on level of primary caregiver's oral health literacy, and systematic education should be preceded to enhance the literacy of the caregiver. It is considered necessary to improve the oral health care of children by developing a manual for oral health care education to enhance primary caregiver's oral health literacy.
\end{abstract}

Key Words: Dental health education, Oral health, Health literacy, Health behavior, Preschool child

\section{Introduction}

Young children refer to the children in their first half of preschool age between 2 to 6 years old, which is a period of active growth and development. Oral health care in young children sets the basis for a lifetime and affects the quality of life for oral health ${ }^{1)}$. Dental caries in primary teeth occur frequently in young children due to increased mastication with a full set of primary teeth at about 36 months of age with high susceptibility ${ }^{2}$. Dental caries in primary teeth also cause the development of subsequent permanent teeth, and early loss of primary teeth due to dental caries can lead to disturbances of mastication and maxillofacial development ${ }^{3}$. As a result of the oral health survey of the children in South Korea, the ratio of children with dental caries experience among 5-year-olds decreased from $83.3 \%$ in 2000 to $67.7 \%$ in 2006 and $62.2 \%$ in 2012 , and then increased to $68.5 \%$ in 2018 . The ratio of children with dental caries experience among 12-year-olds also decreased from $77.1 \%$ in 2000 to $61.1 \%$ in $2006,57.3 \%$ in 2012, and $56.4 \%$ in 2018 . However, the children with dental caries experience still accounted for 
more than half of 12-year-olds, indicating that many children were experiencing dental caries; the decayed, missing, and filled teeth (DMFT) index was 1.84 in 2018, still higher than the OECD (Organisation for Economic Co-operation and Development) average of $1.2^{4)}$. Oral health refers to a condition in which the oral cavity can perform its functions ${ }^{3)}$. Oral health care in young children will be the starting point for continuous oral health care in the future. Even the primary teeth to be replaced with permanent teeth must be properly managed, and proper oral care must be provided by treating any dental caries at an appropriate time ${ }^{2,3)}$. Therefore, oral health care education appropriate to the growth stage must be provided, and such education leads to changes in the behavior, knowledge, and attitude of oral health care ${ }^{5)}$. The responsible concern and attitude of caregivers for oral health care of young children are very important as it is difficult to expect young children to engage in voluntary oral care, and they tend to have low motivation for oral care $^{6,7)}$. Previous studies have reported a high correlation with parents in determining the oral health status and behavioral knowledge of young children, and the parents of young children with good oral health and behavior have been reported to have better oral health knowledge and oral health behavior than the parents of young children who do not ${ }^{8-10)}$. In particular, among the caregivers, mothers spend a lot of time with their children in daily life, and play a central role in oral health care such as dental checkups and treatments ${ }^{11)}$. The oral health awareness for children was higher in mothers than for in caregivers, and the oral health knowledge and behavior of the mothers were reported to have a strong correlation with the oral health behavior of the children ${ }^{12-14)}$. Literacy refers to the ability to understand health information, and is an ability required for individuals to make appropriate medical choices (Office of Disease Prevention and Health Promotion, 2000). Low health literacy makes it difficult for one to access medical services, thereby resulting in poor health $^{15)}$. The same applies for oral health; the higher the health literacy is, the better the oral health is, with more positive oral health behavior ${ }^{16)}$. In this respect, oral health literacy seems to have an effect on oral health, and it is important to find out the level of oral health literacy of caregivers who are nurturing young children, laying the cornerstone of lifelong oral care. However, the existing studies on oral health literacy have been conducted mostly in some adults and elementary school students, and there is an insufficient number of studies on oral health literacy in caregivers of young children. Therefore, this study aims to understand the oral health literacy of mothers who are the main caregivers of young children, to investigate the effects of oral health literacy of mothers on the oral health and behavior preschool children, and to provide the basic data for the development of oral health programs by level according to the oral health literacy of caregivers for promoting oral health of young children.

\section{Materials and Methods}

\section{Subjects}

The survey was conducted from September 1 to 14 , 2020. As a result of calculating the minimum sample size using the $\mathrm{G}^{*}$ POWER 3.1 program, the total number of subjects was 204 (significance level of 0.05 , effect size of 0.15 , and power of 0.95 ). Therefore, this study attempted to reduce the sample error as much as possible, and to select the subjects in consideration of the bias or $10 \%$ dropout rate of $10 \%$ of the sample. This study selected 201 caregivers of preschool children as subjects by convenient sampling with the cooperation of daycare centers and kindergartens in the $\mathbf{J}$ region. Subjects were provided with the explanation of the purpose and content of the study; if the subjects agreed to participate, they were asked to fill in the self-reported questionnaire distributed online. Of the data of 201 subjects surveyed, the data of 192 subjects were used for the final analysis, excluding data with many missing values.

\section{Research tool}

A structured questionnaire was used in this study by modifying and supplementing the content based on the research tools used in previous studies ${ }^{17-22)}$. The questionnaire for the caregivers consisted of 36 items in total: 4 items on the general characteristics including age, level of education, employment status, and number of children; 5 items on the oral health behavior including the time of oral health 
education, oral pain in children, experience in oral health education, time of oral health education, and channel of oral health education; 10 items on verbal oral health literacy; 7 items on functional oral health literacy; and 10 items on oral health care behavior for children.

As for the tool to measure verbal oral health literacy, the researcher of this study modified and supplemented the Rapid Estimate of Adult Literacy in Dentistry (REALD) modified and supplemented by Lee ${ }^{17)}$ and Ju et al. ${ }^{18)}$ based on the terminology commonly used in dental treatment for children. The answers to the items were scored according to the scoring method in the study by Lee ${ }^{17)}: 1$ point for "I know exactly what it means," and 0 point for "I have heard of it but do not know what it means" or "I do not know exactly what it means." A higher score means higher verbal oral health literacy. Cronbach's $\alpha$ was 0.926 for the verbal oral health literacy in this study.

The measurement tool modified and supplemented by Lee ${ }^{17)}$ based on the Test of Functional Health Literacy in Dentistry (TOFHLiD) developed by Gong et al. ${ }^{19)}$, revised and modified by $\mathrm{Ju}$ et $\mathrm{al}^{20}{ }^{20}$, and the tool modified and supplemented by Kang and $\mathrm{Cho}^{22)}$ based on the Oral health Literacy Instrument for Korean Children's Caregiver (OHLIKCC) developed by $\mathrm{Ryu}^{21)}$ were used for measuring functional oral health literacy. There were 7 items in total: 2 items on scaling (Cronbach's $\alpha=0.674$ ), 3 questions on dental sealant (Cronbach's $\alpha=0.711$ ), and 2 questions on fluorine varnish (Cronbach's $\alpha=0.710$ ). For each item, 1 point was given for each correct answer, and 0 point for each incorrect answer.

\section{Data analysis}

The item discrimination was measured by the contingency coefficient; the higher the division coefficient was, the higher the item discrimination was. The item discrimination was evaluated based on the level of item discrimination by Ebel and Frisbie ${ }^{23)}$. As for the discriminative index, 0.10 to less than 0.20 indicated low item discrimination, 0.20 to less than 0.30 indicated slightly low item discrimination, 0.30 to less than 0.40 indicated moderate item discrimination, and 0.40 or higher indicated high item discrimination.

Differences in verbal and functional oral health literacy according to sociodemographic factors, differences in verbal and functional oral health literacy according to oral health behavior and oral health education of the caregivers, and differences in verbal and functional oral health literacy according to oral health care behavior of caregivers for children were examined by t-test (independent t-test) and analysis of variance (one-way ANOVA); the effects of sociodemographic factors associated with the caregivers and oral health care behavior of the caregivers for the children on verbal and functional oral health literacy were examined by multiple regression analysis. The significance level $(\alpha)$ used for the statistical test was 0.05 , and the collected data were analyzed using the SPSS Statistics version 25.0 (IBM Corp., Armonk, NY, USA) program.

Table 1. Item Difficulty and Item Discrimination of Verbal Oral Health Literacy $(n=201)$

\begin{tabular}{lcccc}
\hline \multicolumn{1}{c}{ Item } & Correct answers & Item difficulty & Item discrimination & $\begin{array}{c}\text { Item discrimination } \\
\text { assessment }\end{array}$ \\
\hline Dental plaque & $37(18.4)$ & 0.184 & 0.57 & High \\
Tooth sealant & $86(42.8)$ & 0.428 & 0.75 & High \\
Dental calculus & $117(58.2)$ & 0.582 & 0.83 & High \\
Fluorine & $98(48.8)$ & 0.488 & 0.80 & High \\
Eruption of teeth & $35(17.4)$ & 0.174 & 0.47 & High \\
Milk tooth & $113(56.2)$ & 0.562 & 0.84 & High \\
Permanent tooth & $118(58.7)$ & 0.587 & 0.84 & High \\
Tooth extraction & $117(58.2)$ & 0.582 & 0.80 & High \\
G.I & $26(12.9)$ & 0.129 & 0.49 & High \\
Dental resin & $84(41.8)$ & 0.418 & 0.76 & High \\
\hline
\end{tabular}

Values are presented as number (\%).

G.I: glass ionomer. 


\section{Results}

\section{Difficulty and discrimination of verbal and functional oral health literacy items}

Table 1 shows the difficulty and discrimination of the items on verbal oral health literacy. The item asking the time when children could eat after receiving fluoride varnish showed high discrimination with the contingency coefficient of 0.41 , followed by the item asking the time to drink water after receiving fluoride varnish for maximizing the effect with contingency coefficient of 0.36 and the item asking the correct behavior after receiving dental scaling with contingency coefficient of 0.30 . The item on permanent teeth showed the highest correct answer rate at $58.7 \%$, followed by the items on extraction and dental calculus each with the correct answer rate of $58.2 \%$.

Table 2 shows the difficulty and discrimination of the items on functional oral health literacy. All items had adequate discrimination with a contingency coefficient of 0.40 or higher, and the items on primary teeth and permanent teeth showed highest discrimination with the contingency coefficient of 0.84 . The item asking the purpose of dental sealant showed the highest correct answer rate at $99.4 \%$, followed by the item asking the time

Table 2. Item Difficulty and Item Discrimination of Functional Oral Health Literacy $(n=201)$

\begin{tabular}{lcccc}
\hline \multicolumn{1}{c}{ Item } & $\begin{array}{c}\text { Correct } \\
\text { answers }\end{array}$ & $\begin{array}{c}\text { Item } \\
\text { difficulty }\end{array}$ & $\begin{array}{c}\text { Item } \\
\text { discrimination }\end{array}$ & $\begin{array}{c}\text { Item } \\
\text { discrimination } \\
\text { assessment }\end{array}$ \\
\hline Correct behavior after scaling & $164(81.6)$ & 0.815 & 0.30 & Middle \\
Knowledge related to scaling & $129(65.8)$ & 0.618 & 0.21 & Low \\
Purpose of tooth sealant & $174(99.4)$ & 0.994 & 0.21 & Low \\
Treatment area of tooth sealant & $138(68.7)$ & 0.686 & 0.18 & Few \\
A routine medical examination period of tooth sealant & $171(85.1)$ & 0.850 & 0.12 & Few \\
Time to eat after fluoride varnish & $132(65.7)$ & 0.656 & 0.41 & High \\
Water intake time for maximum effect after fluoride application & $138(68.7)$ & 0.686 & 0.36 & Middle \\
\hline
\end{tabular}

Values are presented as number $(\%)$.

Table 3. Differences in Oral Health Literacy according to Demographic Sociological Factors ( $n=200)$

\begin{tabular}{|c|c|c|c|c|}
\hline \multicolumn{2}{|c|}{ Item } & \multirow{2}{*}{$\begin{array}{c}\text { Number of } \\
\text { patients }\end{array}$} & \multirow{2}{*}{$\begin{array}{c}\text { Verbal oral health literacy } \\
2.94 \pm 1.99\end{array}$} & \multirow{2}{*}{$\begin{array}{c}\text { Functional oral health literacy } \\
\qquad 4.60 \pm 1.81\end{array}$} \\
\hline Age (y) & $20 \sim 29$ & & & \\
\hline & $30 \sim 39$ & 112 & $4.92 \pm 1.23$ & $5.75 \pm 1.12$ \\
\hline & $\geq 40$ & 37 & $5.63 \pm 1.59$ & $4.82 \pm 1.80$ \\
\hline & $\mathrm{p}$-value & & 0.013 & 0.204 \\
\hline \multirow[t]{4}{*}{ Education } & High school & 24 & $3.75 \pm 1.20$ & $5.41 \pm 1.53$ \\
\hline & College & 80 & $4.15 \pm 1.46$ & $5.52 \pm 1.39$ \\
\hline & $\geq$ University & 96 & $5.17 \pm 1.84$ & $5.67 \pm 1.28$ \\
\hline & $\mathrm{p}$-value & & 0.002 & 0.040 \\
\hline \multirow[t]{4}{*}{ Occupation } & Housewife & 57 & $5.35 \pm 1.13$ & $5.69 \pm 1.34$ \\
\hline & Full-time work & 105 & $4.23 \pm 1.11$ & $5.64 \pm 1.24$ \\
\hline & Part-time work & 38 & $4.87 \pm 1.27$ & $5.23 \pm 1.63$ \\
\hline & $\mathrm{p}$-value & & 0.055 & 0.050 \\
\hline \multirow[t]{4}{*}{ The number of children } & 1 & 112 & $3.93 \pm 1.13$ & $5.58 \pm 1.37$ \\
\hline & 2 & 75 & $5.22 \pm 1.05$ & $5.68 \pm 1.18$ \\
\hline & $\geq 3$ & 13 & $7.00 \pm 1.74$ & $5.00 \pm 1.95$ \\
\hline & p-value & & 0.016 & 0.167 \\
\hline
\end{tabular}

Values are presented as number only or mean \pm standard deviation.

p-values calculated by ANOVA or t-test. 
of regular check-up after receiving dental sealant with the correct answer rate of $85.1 \%$.

\section{Differences in verbal and functional oral health literacy according to sociodemographic factors}

Table 3 shows the differences in verbal and functional oral health literacy according to sociodemographic factors. The verbal oral health literacy according to sociodemographic factors was statistically significant in the items on age, level of education, and number of children $(\mathrm{p}<0.05)$. The older the mother, the higher the level of education, and the larger the number of children was, the higher the verbal literacy was.

The functional oral health literacy according to sociodemographic factors was statistically significant in the item on level of education $(p<0.05)$. The higher the level of education was, the higher the functional literacy was.

\section{Differences in verbal and functional oral health literacy according to oral health behavior for children and oral health education of mothers}

Table 4 shows the differences in verbal and functional oral health literacy according to oral health behavior for children and oral health education of mothers. The verbal oral health literacy according to oral health behavior for children and oral health education was statistically significant in the items on oral pain in children, experience in oral health education, time of oral health education, and channel of oral health education $(p<0.05)$. If the children did not complain of pain in the oral cavity, or if the caregivers had received oral health education, the caregivers demonstrated high verbal literacy; those within one to two years from receiving oral health education showed high verbal literacy; and those who received oral health education from an expert or a dental clinic showed high verbal literacy.

The functional oral health literacy according to oral health behavior for children and oral health education was statistically significant in the items on oral pain in children and experience in oral health education $(\mathrm{p}<0.05)$. If the children had not experienced pain in the oral cavity, or if

Table 4. Differences in Oral Health Literacy according to Oral Health Behavior and Oral Health Education Status ( $\mathrm{n}=200$ )

\begin{tabular}{|c|c|c|c|c|}
\hline Item & & $\begin{array}{c}\text { Number of } \\
\text { patients }\end{array}$ & $\begin{array}{c}\text { Verbal oral } \\
\text { health literacy }\end{array}$ & $\begin{array}{c}\text { Functional oral health } \\
\text { literacy }\end{array}$ \\
\hline \multirow[t]{3}{*}{ Visit your child's dentist for the past year } & Yes & 143 & $4.47 \pm 1.12$ & $5.67 \pm 1.34$ \\
\hline & No & 57 & $5.10 \pm 1.20$ & $5.35 \pm 1.36$ \\
\hline & p-value & & 0.074 & 0.158 \\
\hline \multirow[t]{3}{*}{ Child's oral pain for the past year } & Yes & 72 & $4.17 \pm 1.58$ & $5.26 \pm 1.34$ \\
\hline & No & 128 & $4.80 \pm 1.96$ & $5.76 \pm 1.33$ \\
\hline & p-value & & 0.042 & 0.030 \\
\hline \multirow[t]{3}{*}{ Mother's oral health education } & Yes & 130 & $5.00 \pm 1.06$ & $5.58 \pm 1.35$ \\
\hline & No & 70 & $3.97 \pm 1.21$ & $4.58 \pm 1.37$ \\
\hline & p-value & & 0.027 & 0.047 \\
\hline \multirow[t]{4}{*}{ Period of oral health education $(y)$} & Within $1 \sim 2$ & 74 & $4.97 \pm 1.07$ & $5.67 \pm 1.14$ \\
\hline & Within $3 \sim 5$ & 48 & $4.14 \pm 1.94$ & $5.62 \pm 1.51$ \\
\hline & $\geq 6$ & 24 & $3.64 \pm 1.43$ & $4.89 \pm 1.53$ \\
\hline & p-value & & 0.037 & 0.408 \\
\hline \multirow[t]{3}{*}{ Provide oral health education } & Expert (dental) & 108 & $5.14 \pm 1.11$ & $5.52 \pm 1.37$ \\
\hline & Other & 34 & $3.60 \pm 1.14$ & $5.71 \pm 1.08$ \\
\hline & p-value & & 0.001 & 0.210 \\
\hline
\end{tabular}

Values are presented as number only or mean \pm standard deviation. p-values calculated by ANOVA or t-test. 
the caregivers had received oral health education, the caregivers demonstrated high functional literacy.
4. Differences in verbal and functional oral health literacy according to oral health care behavior of caregivers for children

Table 5 shows the differences in verbal and functional oral health literacy according to oral health care behavior

Table 5. Differences in Oral Health Literacy according to the Oral Health Care of the Mother's Children ( $n=200)$

\begin{tabular}{|c|c|c|c|c|}
\hline Item & & $\begin{array}{c}\text { Number of } \\
\text { patients }\end{array}$ & $\begin{array}{c}\text { Verbal oral health } \\
\text { literacy }\end{array}$ & $\begin{array}{l}\text { Functional oral health } \\
\text { literacy }\end{array}$ \\
\hline \multirow[t]{4}{*}{ Toothbrush your child after snack } & Not & 33 & $2.93 \pm 1.38$ & $5.77 \pm 2.36$ \\
\hline & Usually & 59 & $5.35 \pm 1.15$ & $5.10 \pm 1.64$ \\
\hline & Yes & 108 & $4.82 \pm 1.95$ & $5.77 \pm 1.10$ \\
\hline & p-value & & 0.070 & 0.120 \\
\hline \multirow[t]{4}{*}{ Toothbrush your child after a meal } & Not & 19 & $3.38 \pm 1.75$ & $5.56 \pm 1.55$ \\
\hline & Usually & 50 & $5.11 \pm 1.19$ & $5.42 \pm 1.37$ \\
\hline & Yes & 131 & $4.64 \pm 1.05$ & $5.64 \pm 1.32$ \\
\hline & p-value & & 0.025 & 0.050 \\
\hline \multirow[t]{4}{*}{ Toothbrush your child before bedtime } & Not & 9 & $1.00 \pm 1.25$ & $6.14 \pm 1.07$ \\
\hline & Usually & 25 & $5.91 \pm 1.06$ & $5.17 \pm 1.40$ \\
\hline & Yes & 166 & $4.76 \pm 1.08$ & $5.62 \pm 1.35$ \\
\hline & p-value & & 0.022 & 0.058 \\
\hline \multirow[t]{4}{*}{ Restriction on intake of sugar-added foods } & Not & 36 & $2.88 \pm 1.96$ & $5.42 \pm 1.06$ \\
\hline & Usually & 86 & $5.53 \pm 1.96$ & $5.55 \pm 1.45$ \\
\hline & Yes & 78 & $4.47 \pm 1.20$ & $5.69 \pm 1.36$ \\
\hline & p-value & & 0.089 & 0.096 \\
\hline \multirow[t]{4}{*}{ Food intake restriction before bed } & Not & 34 & $2.88 \pm 1.19$ & $5.45 \pm 1.35$ \\
\hline & Usually & 58 & $4.93 \pm 1.22$ & $5.34 \pm 1.40$ \\
\hline & Yes & 108 & $4.73 \pm 1.06$ & $5.74 \pm 1.32$ \\
\hline & p-value & & 0.043 & 0.021 \\
\hline \multirow[t]{4}{*}{ Restriction on consumption of cavity-inducing foods } & Not & 51 & $1.81 \pm 1.41$ & $5.21 \pm 1.52$ \\
\hline & Usually & 74 & $6.56 \pm 1.44$ & $5.61 \pm 1.29$ \\
\hline & Yes & 75 & $4.52 \pm 1.18$ & $5.78 \pm 1.27$ \\
\hline & p-value & & 0.058 & $<0.001$ \\
\hline \multirow[t]{4}{*}{ Check after brushing your child's teeth } & Not & 37 & $3.33 \pm 1.22$ & $5.36 \pm 1.39$ \\
\hline & Usually & 73 & $4.68 \pm 1.29$ & $5.44 \pm 1.47$ \\
\hline & Yes & 90 & $5.08 \pm 1.96$ & $5.78 \pm 1.22$ \\
\hline & p-value & & 0.019 & 0.054 \\
\hline \multirow[t]{4}{*}{ Teach the right way to brush teeth } & Not & 20 & $1.80 \pm 1.49$ & $5.61 \pm 1.04$ \\
\hline & Usually & 72 & $5.17 \pm 1.31$ & $5.52 \pm 1.45$ \\
\hline & Yes & 108 & $4.64 \pm 1.05$ & $5.61 \pm 1.35$ \\
\hline & p-value & & 0.084 & 0.154 \\
\hline \multirow[t]{4}{*}{ Use fluoride toothpaste } & Not & 44 & $3.62 \pm 1.13$ & $5.46 \pm 1.39$ \\
\hline & Usually & 74 & $4.66 \pm 1.07$ & $5.46 \pm 1.55$ \\
\hline & Yes & 82 & $4.95 \pm 1.22$ & $5.75 \pm 1.12$ \\
\hline & p-value & & 0.048 & 0.083 \\
\hline \multirow[t]{4}{*}{ Tongue brushing } & Not & 13 & $1.00 \pm 2.12$ & $5.25 \pm 1.86$ \\
\hline & Usually & 54 & $5.33 \pm 1.43$ & $5.71 \pm 1.26$ \\
\hline & Yes & 133 & $4.56 \pm 1.03$ & $5.55 \pm 1.33$ \\
\hline & p-value & & 0.064 & 0.402 \\
\hline
\end{tabular}

Values are presented as number only or mean \pm standard deviation. p-values calculated by ANOVA or t-test. 
of caregivers for children.

The verbal oral health literacy according to oral health care behavior of caregivers for children was statistically significant in the items on teaching children to brush teeth after eating, teaching children to brush teeth before going to bed, limiting food intake before bedtime, checking the oral cavity of children after toothbrushing, and guiding children to use fluoride toothpaste $(\mathrm{p}<0.05)$. The verbal literacy was 4.64 points for the group teaching children to brush teeth after each meal, 5.11 points for the group of moderate practice, and 3.38 points for the group not teaching children to brush teeth after each meal. The verbal literacy was 4.76 points for the group teaching children to brush teeth before going to bed, 5.91 points for the group of moderate practice, and 1.00 points for the group not teaching children to brush teeth before going to bed. The verbal literacy was 4.73 points for the group limiting food intake of children before bedtime, 4.93 points for the group of moderate practice, and 2.88 points for the group not teaching children to brush teeth before going to bed. The verbal literacy was 5.08 points for the group checking the oral cavity of children after toothbrushing, 4.68 points for the group of moderate practice, and 3.33 points for the group not checking the oral cavity of children after toothbrushing. The verbal literacy was 4.95 points for the group guiding children to use fluoride toothpaste, 4.66 points for the group of moderate practice, and 3.62 points for the group not guiding children to use fluoride toothpaste.

The functional oral health literacy according to oral health care behavior of caregivers for children was statistically significant in the items on limiting food intake before bedtime and limiting cariogenic food intake $(\mathrm{p}<$ $0.05)$. The functional oral health literacy was 5.74 points for the group limiting food intake before bedtime, and 5.45 points for the group not limiting food intake before

Table 6. Effects of Demographic Sociological Factors and Children's Oral Health Management on Oral Health Literacy

\begin{tabular}{|c|c|c|c|c|c|c|c|c|}
\hline \multirow{3}{*}{ Item } & \multicolumn{4}{|c|}{ Verbal oral health literacy } & \multicolumn{4}{|c|}{ Functional oral health literacy } \\
\hline & \multicolumn{2}{|c|}{ Model 1} & \multicolumn{2}{|c|}{ Model 2} & \multicolumn{2}{|c|}{ Model 1} & \multicolumn{2}{|c|}{ Model 2} \\
\hline & $\beta$ & p-value & $\beta$ & p-value & $\beta$ & p-value & $\beta$ & p-value \\
\hline Age & 0.238 & 0.041 & 0.759 & 0.065 & -0.170 & 0.226 & -0.157 & 0.388 \\
\hline Education & 0.138 & 0.056 & 0.686 & 0.046 & 0.318 & 0.016 & 0.388 & 0.020 \\
\hline Occupation & 0.217 & 0.307 & 0.994 & 0.053 & -0.106 & 0.421 & -0.125 & 0.459 \\
\hline The number of children & 0.182 & 0.050 & 0.967 & 0.100 & -0.136 & 0.325 & -0.124 & 0.479 \\
\hline $\begin{array}{l}\text { Toothbrush your child after } \\
\text { snack }\end{array}$ & & & 0.604 & 0.427 & & & -0.117 & 0.052 \\
\hline $\begin{array}{l}\text { Toothbrush your child after a } \\
\text { meal }\end{array}$ & & & 0.252 & 0.059 & & & 0.106 & 0.683 \\
\hline $\begin{array}{l}\text { Toothbrush your child before } \\
\text { bedtime }\end{array}$ & & & 0.966 & 0.034 & & & -0.151 & 0.521 \\
\hline $\begin{array}{l}\text { Restriction on intake of } \\
\text { sugar-added foods }\end{array}$ & & & 0.040 & 0.886 & & & 0.183 & 0.383 \\
\hline $\begin{array}{l}\text { Food intake restriction before } \\
\text { bed }\end{array}$ & & & 0.512 & 0.366 & & & 0.133 & 0.050 \\
\hline $\begin{array}{l}\text { Restriction on consumption of } \\
\text { cavity-inducing foods }\end{array}$ & & & 0.370 & 0.068 & & & 0.171 & 0.025 \\
\hline $\begin{array}{l}\text { Check after brushing your } \\
\text { child's teeth }\end{array}$ & & & 0.212 & 0.050 & & & 0.065 & 0.741 \\
\hline $\begin{array}{l}\text { Teach the right way to brush } \\
\text { teeth }\end{array}$ & & & 0.250 & 0.235 & & & -0.014 & 0.956 \\
\hline Use fluoride toothpaste & & & 0.346 & 0.396 & & & 0.020 & 0.922 \\
\hline Tongue brushing & & & 0.265 & 0.108 & & & 0.100 & 0.650 \\
\hline $\mathrm{R}^{2}$ & \multicolumn{2}{|c|}{0.094} & \multicolumn{2}{|c|}{0.864} & \multicolumn{2}{|c|}{0.189} & \multicolumn{2}{|c|}{0.314} \\
\hline Adjusted $\mathrm{R}^{2}$ & \multicolumn{2}{|c|}{0.119} & \multicolumn{2}{|c|}{0.747} & \multicolumn{2}{|c|}{0.125} & \multicolumn{2}{|c|}{0.208} \\
\hline
\end{tabular}

p-value calculated by logistic regression. 
bedtime. The verbal literacy was 5.78 points for the group limiting cariogenic food intake, 5.61 points for the group of moderate practice, and 5.21 points for the group not limiting cariogenic food intake.

\section{Effects of sociodemographic factors and oral health care behavior of caregivers for children on verbal and functional oral health literacy}

Table 6 shows the effects of sociodemographic factors associated with the caregivers and oral health care behavior of the caregivers for the children on verbal and functional oral health literacy.

In Model 1, in which sociodemographic factors were used as independent variables to investigate the effects of sociodemographic factors of the caregivers and oral health care behavior for the children on verbal oral health literacy, the older the caregivers was, the higher the verbal oral health literacy was $(\mathrm{p}<0.05)$. In Model 2 , in which sociodemographic factors and oral health care behavior for the children were used as independent variables, the higher the level of education was, and the more the children were taught to brush teeth before going to bed, the higher the verbal oral health literacy was $(\mathrm{p}<0.05)$.

In Model 1, in which sociodemographic factors were used as independent variables to investigate the effects of sociodemographic factors of the caregivers and oral health care behavior for the children on verbal oral health literacy, the higher the level of education, the higher the functional oral health literacy was $(\mathrm{p}<0.05)$. In Model 2, in which sociodemographic factors and oral health care behavior for the children were used as independent variables, the higher the level of education was and the more the children were limited to consume cariogenic food, the higher the verbal oral health literacy was $(\mathrm{p}<$ 0.05).

\section{Discussion}

Young children undergo overall physical development, and oral health is very important to maintain healthy physical development. Although young children consume a lot of sugary foods, they are at high risk of dental caries as they have difficulty in voluntary oral health care due to immature motor neuron development ${ }^{24)}$. As the negligence of oral care in early childhood may result in oral health problems throughout life, it can be seen as the time to lay the cornerstone of lifelong oral care. In order to maintain oral health in early childhood, proper oral health education must be provided. Oral health education during this period is mainly conducted by caregivers to build the ability to manage oral health in young children ${ }^{8-10}$. The role of caregivers seemed essential in oral health care of young children; therefore, this study aimed to provide a basis for the development of oral health programs by level according to the oral health literacy of caregivers. As for the difficulty and discrimination of the items on verbal oral health literacy, the item on permanent teeth showed the highest correct answer rate, followed by the items on extraction and tartar. While such results were similar to the correct answer rates reported by $\mathrm{Ju}$ et al. ${ }^{20)}$, the correction answer rate for the item on dental plaque was $18.4 \%$, still leaving much to be desired in terms of verbal oral health literacy for many items. As for the difficulty and discrimination of the items on functional oral health literacy, the items asking the purpose of dental sealant and the time of regular check-up after receiving dental sealant showed high correct answer rates. The high correct answer rate may have been caused by the designation of dental sealant as a reimbursable item of the health insurance. However, the correct answer rate of the item asking the time when children could eat after receiving fluoride varnish was $65.7 \%$, and that of the item asking the time to drink water after receiving fluoride varnish for maximizing the effect was $68.7 \%$. This may have been caused by insufficient awareness of caregivers about fluoride varnish, suggesting the need for providing the information on fluoride varnish to caregivers. The difference in verbal and functional oral health literacy according to sociodemographic factors was statistically significant in the item on level of education, in line with the result of the study by Kang and $\mathrm{Cho}^{22)}$, but there was no difference in verbal and functional oral health literacy according to the age of caregivers. Caregivers taking care of more children had higher verbal literacy, and housewives had higher functional literacy. It is easy to access dental information 
through dental clinic visits, parenting books, and the Internet searches, and caregivers of multiple children may have high verbal literacy based on the information obtained from nurturing the older children. As housewives may have high functional literacy as they spend more time with children than the caregivers who go to work.

As for the differences in verbal and functional oral health literacy according to oral health behavior and oral health education of mothers, if the children had not experienced pain in the oral cavity, or if the caregivers had received oral health education, the mothers demonstrated high verbal and functional literacy, and those within one to two years from receiving oral health education showed high verbal literacy. In the results of the study by Jung and $\mathrm{Jun}^{3)}$, experience of mothers in oral health education affected the oral health behavior of children, and the caregivers could have prevented any problem in oral health of children based on high oral health literacy. Since the first national oral health screening program for infants and children in South Korea held twice in 2007, and the oral check-ups have been expanded to three times, from 18 to 29 months, from 42 to 53 months, and from 54 to 65 months. The national oral health screening program for infants and children consists of examination by interview, oral examination, and oral health education. In spite that it was an opportunity not only to prevent oral diseases by early treatment and detection of oral diseases based on the oral examination of young children, but also to receive oral health education and counseling by age, the participation rate of the national oral health screening program for infants and children was $45.2 \%$ as of 2018 , showing a low screening rate of less than half ${ }^{25)}$. Considering that those who received oral health education from an expert or a dental clinic showed high verbal literacy, It seems necessary to come up with active promotion and measures for improving the screening rate of the national oral health screening program for infants and children to enhance the oral health literacy of caregivers by receiving periodic oral health education at the dental clinic.

The differences in verbal and functional oral health literacy according to oral health care behavior of caregivers for children were statistically significant in the items on limiting food intake before bedtime. This was in line with the results of the study by Kang and $\mathrm{Cho}^{22)}$ reporting low numbers of teeth with dental caries and restored teeth, suggesting that the oral health behavior of caregivers affected the oral health behavior of children. However, as for the oral health behavior of caregivers, the literacy for the items on teaching children to brush teeth after eating snack, limiting intake if cariogenic food, and guiding children to practice proper toothbrushing. The study by $\mathrm{Cho}^{26}$ reported that parents should have confidence in their oral health knowledge and behavior in order to cultivate oral health behavior in children. To this end, caregivers need to improve oral health literacy by providing oral health education for children.

As for the effects of sociodemographic factors of the caregivers and oral health care behavior for the children on verbal and functional oral health literacy, the results obtained by inputting the sociodemographic factors and oral health care behavior as independent variables were similar to the results of differences in literacy according to sociodemographic factors and the results of differences in literacy according to the oral health care behavior of the caregivers for the children, indicating a correlation. Park and $\mathrm{Kang}^{27)}$ reported that the higher the level of education was in mothers, the more significant differences were found in the oral care practice of young children, which might have caused the high oral health literacy in early childhood with a higher level of education in caregivers. Ryu et al. ${ }^{28)}$ reported that the oral health knowledge and behavior of mothers influenced the oral health of children; Sim et al. ${ }^{29)}$ reported that those with higher level of oral health knowledge not only managed their own oral health to prevent the development of oral diseases, but also affected their family. As a result of study, the oral health in young children depends on the role of caregivers in oral health care. The higher the oral health literacy of caregivers was, the more impact the caregivers had on the oral health behavior of children. Therefore, it would be necessary to devise various measures according to sociodemographic factors to enhance the oral health literacy of caregivers.

This study had limitations in that, despite the rise in the research on oral health literacy, the development of 
research tools for literacy skills was insufficient, and the age groups of the subjects were not diverse enough. Since this study limited the range of subjects to the mothers, who were the main caregivers, future research would be required to supplement the research tools and the research subjects. However, this study is meaningful in that there has been insufficient number of studies on the oral health behavior of young children according to the literacy of caregivers while there have been many studies on oral health literacy of adults. As a result of study, the understanding of verbal and functional literacy was essential for improving the oral health literacy of mothers, the main caregivers, and the oral health literacy of mothers affected children. Therefore, it would be necessary to develop systematic programs considering the characteristic of oral development in young children according to the oral health literacy of caregivers, and it should be preceded by systematic education to improve the oral health literacy of caregivers. Based on the result that those who received oral health education from an expert or a dental clinic showed high verbal oral health literacy, it would be necessary to prepare the measures to improve the screening rate of the national oral health screening program for infants and children. There seems to be a need to improve the oral health of children by developing an oral health education manual to enhance the oral health literacy of caregivers through the national oral health screening program for infants and children.

\section{Notes}

\section{Conflict of interest}

No potential conflict of interest relevant to this article was reported.

\section{Ethical approval}

This study was approved by the Wonkwang University Bioethics Review Committee (IRB No. WKIRB-202008SB-045).

\section{Author contributions}

Conceptualization: Mi-Jeong Kim. Data acquisition: Mi-Jeong Kim. Formal analysis: Cha-Young Lim. Funding: Mi-Jeong
Kim. Supervision: Mi-Jeong Kim. Writing-original draft: Ju-Lee Son. Writing — review \& editing: Cha-Young Lim.

\section{ORCID}

Mi-Jeong Kim, https://orcid.org/0000-0002-5309-1853

Cha-Young Lim, https://orcid.org/0000-0001-9345-7349

Ju-Lee Son, https://orcid.org/0000-0003-4611-8891

\section{Acknowledgements}

This research was supported by funds of Vision College of Jeonju.

\section{References}

1. de Silva AM, Hegde S, Akudo Nwagbara B, et al.: Communitybased population-level interventions for promoting child oral health. Cochrane Database Syst Rev (12): CD009837, 2016. https://doi.org/10.1002/14651858.CD009837.pub3

2. Public Oral Health Textbook Development Committee: Public oral health. 5th ed. Komoonsa, Seoul, pp.41-56, 2019.

3. Jung $\mathrm{MH}$, Jun SH: A child oral care state according to mother's oral health education experience- selected preschool in Daegu metropolitan city. J Korean Soc Dent Hyg 10: 965-972, 2010.

4. Retrieved November 18, 2020, from http://www.mohw.go.

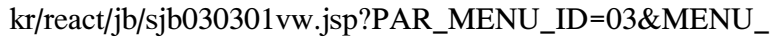
ID $=032901 \&$ CONT_SEQ=349651.pdf(2019).

5. Kang BH, Park SN, Sohng KY, Moon JS: Effect of a tooth-brushing education program on oral health of preschool children. J Korean Acad Nurs 38: 914-922, 2008. https://doi.org/10.4040/jkan.2008.38.6.914

6. Han SJ, Moon HS, Jung JY, et al.: Parents' oral health awareness and behaviors of their elementary school children. J Korean Soc Sch Health 14: 107-114, 2001.

7. Lee SN, Kim ES: Comparison between early childhood teachers and mothers in perception of oral health behavior and education for children. J Dent Hyg Sci 13: 125-134, 2013.

8. Petersen PE: Oral health behavior of 6-year-old Danish children. Acta Odontol Scand 50: 57-64, 1992. https://doi.org/10.3109/00016359209012747

9. Okada M, Kawamura M, Kaihara Y, et al.: Influence of parents' oral health behaviour on oral health status of their school children: an exploratory study employing a causal 
modelling technique. Int J Paediatr Dent 12: 101-108, 2002. https://doi.org/10.1046/j.1365-263x.2002.00338.x

10. Poutanen R, Lahti S, Tolvanen M, Hausen H: Parental influence on children's oral health-related behavior. Acta Odontol Scand 64: 286-292, 2006. https://doi.org/10.1080/00016350600714498

11. Lee JH, Ra SJ, Kim JB: Oral health knowledge and practices among housewives at apartment houses in metropolitan area. J Korean Acad Dent Health 20: 509-530, 1996.

12. Kong MS, Lee HS, Kim SN: Children's dental health behavior in relation to their mothers' dental health knowledge level, attitude toward dentist and dental health behaviors. J Korean Acad Dent Health 18: 84-94, 1994.

13. Al-Omiri MK, Al-Wahadni AM, Saeed KN: Oral health attitudes, knowledge, and behavior among school children in North Jordan. J Dent Educ 70: 179-187, 2006. https://doi.org/10.1002/j.0022-0337.2006.70.2.tb04074.x

14. Park CS, Kang EJ, Song JY, Song KS: The influence on infant oral health care from mother's experience of oral health education. J Korean Soc Dent Hyg 12: 1183-1192, 2012. https://doi.org/10.13065/jksdh.2012.12.6.1183

15. Berkman ND, Sheridan SL, Donahue KE, Halpern DJ, Crotty K: Low health literacy and health outcomes: an updated systematic review. Ann Intern Med 155: 97-107, 2011. https://doi.org/10.7326/0003-4819-155-2-201107190-00005

16. Ju HJ, Lee HS, Oh HW: Relationship of oral health literacy with oral health behaviors among adults. J Korean Acad Oral Health 39: 186-194, 2015. https://doi.org/10.11149/jkaoh.2015.39.3.186

17. Lee MY: The measurement tools and related factors for oral health literacy. Unpublished master's thesis, Namseoul University, Cheonan, 2014.

18. Ju HJ, Oh HW, Lee HS: Impact of oral health literacy on oral health-related quality of life among adults. J Korean Acad Oral Health 38: 220-226, 2014. https://doi.org/10.11149/jkaoh.2014.38.4.220

19. Gong DA, Lee JY, Rozier RG, Pahel BT, Richman JA, Vann WF Jr: Development and testing of the Test of Functional Health Literacy in Dentistry (TOFHLiD). J Public Health
Dent 67: 105-112, 2007.

https://doi.org/10.1111/j.1752-7325.2007.00023.x

20. Ju HJ, Oh HW, Lee HS: A cross-sectional study on oral health literacy and its influencing factors among adults: II. Functional oral health literacy. J Korean Acad Oral Health 37: 81-88, 2013.

https://doi.org/10.11149/jkaoh.2013.37.2.81

21. Ryu DY: Development of oral health literacy instrument for Korean children's caregiver. Unpublished doctoral dissertation, Gangneung-Wonju National University, Gangneung, 2013.

22. Kang YM, Cho YS: Impact of mother's oral health literacy on preschool children's oral health status and behavior. J Dent Hyg Sci 16: 26-36, 2016. https://doi.org/10.17135/jdhs.2016.16.1.26

23. Ebel RL, Frisbie DA: Essentials of educational measurement. 5th ed. Prentice Hall, New Jersey, pp.191-197, 1991.

24. Shin MM, Paik DI, Hahn SH, Jin BH, Huh SY: Study on oral health information in the child care literatures. J Korean Soc Matern Child Health 5: 17-28, 2001.

25. Park SW, Park JA, Lee JY, Lee G, Jin BH: Needs of caregivers for national oral health screening for infants and children. J Korean Acad Oral Health 44: 138-143, 2020. https://doi.org/10.11149/jkaoh.2020.44.3.138

26. Cho HR: Knowledge and attitudes towards infant oral health, and related health behavior among parents. Child Health Nurs Res 20: 196-204, 2014 https://doi.org/10.4094/chnr.2014.20.3.196

27. Park GJ, Kang YH: Children's oral health behavior in relation to oral health beliefs of mothers and children. $\mathbf{J}$ Korean Soc Matern Child Health 14: 35-47, 2010. https://doi.org/10.21896/jksmch.2010.14.1.35

28. Ryu K, Jeong SH, Kim JY, Choi YH, Song KB: Effect of mothers' oral health behaviour and knowledge on dental caries in their preschool children. J Korean Acad Oral Health 28: 105-115, 2004.

29. Sim SJ, Kim JB, Paik DI, Moon HS: The Influence of mothers' oral an health knowledge on incidence $d$ treatment of deciduous dental caries among their children. J Korean Acad Oral Health 27: 415-434, 2003. 